\title{
Understanding barriers to clinical management of rape (CMR) services among survivors of rape in crisis settings in Borno state
}

Osasuyi Dirisu

Follow this and additional works at: https://knowledgecommons.popcouncil.org/departments_sbsr-rh

Part of the Demography, Population, and Ecology Commons, International Public Health Commons, and the Sociology of Culture Commons How does access to this work benefit you? Let us know!

\section{Recommended Citation}

Dirisu, Osasuyi. 2020. "Understanding barriers to clinical management of rape (CMR) services among survivors of rape in crisis settings in Borno state," research brief. Abuja: Population Council. 
Sexual and gender-based violence

(SGBV) is a global public health concern

disproportionately affecting women, with negative consequences for their health, well-being, human rights, and equality. $1,2,3,4$

SGBV includes any act perpetrated against an individual that is against that person's will, and is predicated upon gender norms and unequal power relationships'. ${ }^{5}$ These structures are rooted in gender roles that subjugate women as inferior. Gendered societal structures are strengthened during periods of conflict, resulting in increased patterns of violence. ${ }^{6}$

\section{"Gendered societal structures are strengthened during periods of conflict, resulting in increased patterns of violence."}

SGBV occurs in crisis settings where vulnerability is increased and social and legal sanctions are reduced. ${ }^{9}$ Internally Displaced Persons (IDPs) are vulnerable to SGBV both during times of conflict as well as in postconflict settings due to resultant losses of socioeconomic opportunities in addition to housing, security, lack of institutional protection, and familial separation.1,6

Armed attacks in Nigeria's North East zone in the past decade have resulted in the displacement of over two million IDPs, who are forced to reside in camps or host communities. ${ }^{7}$ Utilization of SGBV interventions such as medical and psycho-social support services is low in these settings, likely due to lack of survivors' awareness of any services, in addition to the stigma associated with sexual violence, insufficient trust in governance structures, and lack of self-efficacy for initiating conversations about SGBV with health providers. ${ }^{1,6}$

Over two million people in Nigeria's

North East region have been displaced due to armed attacks in the past decade.

The context of SGBV in the North East of Nigeria is poorly understood, and evidence-based strategies to address the medical and psycho-social recovery needs of survivors are urgently needed.
This study was conducted to document the barriers to access to medical and psycho-social support services for SGBV survivors in Borno state, Nigeria, especially during the critical 72 to 120 hours after assault, for CMR, to provide recommendations for the development of interventions to address both primary and secondary prevention needs among groups vulnerable to SGBV.

\section{METHODS}

Qualitative methods explored and described the context of SGBV and the barriers to health services in four IDP camps in three Local Government Areas (LGAs)-Damboa, Maiduguri, and Jere. The four camps included in this study have a combined population of over 26,000 IDPs.

In-depth Interviews (IDIs) with self-identified survivors of SGBV ages 16 and older who either had previously accessed services, or had never accessed services, recounted their experiences and obtained their opinions of the barriers survivors face in seeking help. Family members or caregivers of survivors who were willing to speak about SGBV issues within their communities and families also participated in IDIs.

Focus Group Discussions (FGDs) with community members in the three LGAs provided their perspectives about SGBV issues within their communities, while Key Informant Interviews (KIIs) with service providers and issue advocates solicited their points of view of the impediments SGBV survivors face in seeking help. A total of 26 IDIs, 14 FGDs, and 19 KIls were conducted.

Due to the sensitive nature of SGBV research, strict measures ensured participant confidentiality.

Ethical approvals were obtained from University of Maiduguri Teaching Hospital Health Research Ethics Committee and the Population Council's Institutional Review Board (IRB).

Qualitative interviews were digitally recorded, transcribed, and analyzed using NVIVO 12 software. Thematic analysis explored emerging patterns and themes within the data. MÉDECINS DU MONDE
POPULATION COUNCIL

Ideas. Evidence. Impact. 


\section{KEY FINDINGS}

\section{Personal factors}

Stigma, low decision-making power by women for their own health care, insufficient awareness of the value of timely CMR access, and fear of the consequences of disclosure (such as divorce or social ostracism) are barriers to timely service access. Survivors who received health education from community health workers that addressed confidentiality concerns and emphasized the importance of timely access were more inclined to seek care immediately after SGBV.

\section{Familial factors}

Prevailing consensus among families is for concealing rape (i.e. a culture of silence) to protect the familial reputations and avoid stigma. Socio-economic factors such as poverty and family indebtedness to potential suitors or benefactors facilitate SGBV and limit both disclosure and help after SGBV events.

\section{Community factors}

Social norms that drive SGBV are rooted in community structures that promote victim-blaming and their loss of respect in the community, including divorce and rejection, in addition to perpetuating the underestimation or disregard of SGBV's physical and psychosocial impacts on its survivors. Community mechanisms for resolving SGBV issues protect men, with sanctions usually placed upon female victims. These perceived and actual consequences of disclosure limit timely access to CMR.

Community mechanisms for resolving SGBV issues protect men, with sanctions usually placed upon female victims.

\section{Institutional factors}

Long waits at clinics, limited hours of operation along with restricted numbers of patients, poor service integration among health care providers, in addition to perceived or real lack of empathy from those providers, combined with a general lack of awareness of CMR services all affect survivor inclinations for seeking timely care. When an attending health worker is male or a language barrier necessitates use of an interpreter, survivors are unlikely to meaningfully engage with the service provider, even if they came to the clinic for CMR services.

The Population Council conducts research and delivers solutions that improve lives around the world. Big ideas supported by evidence: It's our model for global change. popcouncil.org

Please address any inquiries about this study to Dr. Osasuyi Dirisu: odirisu@popcouncil.org

This study was funded by Foundation of the Friends of Médecins du Monde.

\section{RECOMMENDATIONS}

- Increasing awareness of the need for CMR services within 72 to 120 hours after rape and informing women, through community health education programs, about the availability of confidential services is critical for ensuring survivors' care.

- Advocacy within communities by community-based organizations must addresses societal norms that drive SGBV and limit its disclosure.

- Provision of CMR within neutral (i.e. providing general services) spaces at clinics can help address survivors' concerns about being seen accessing services for SGBV at clinics.

- Regardless of the challenges in delivering health service in temporary facilities in IDP camps, instituting client review mechanisms is a valuable way of addressing challenges and improving care.

\section{REFERENCES}

1. Wirtz AL, K Pham, N Glass, S Loochkartt, T Kidane, D Cuspoca et al. 2014. Gender-based Violence in Conflict and Displacement: Qualitative Findings from Displaced Women in Colombia. Confl Health 8(1): 10. https://doi.org/10.1186/1752-1505-8-10

2. Freedman J. 2016. Sexual and Gender-based Violence Against Refugee Women: A Hidden Aspect of the Refugee "Crisis." RH Matters 24(47): 18-26. https://doi.org/10.1016/j.rhm.2016.05.003

3. Gurman TA, RM Trappler, A Acosta, PA McCray, CM Cooper, L Goodsmith. 2014. 'By Seeing with Our Own Eyes, It Can Remain in Our Mind': Qualitative Evaluation Findings Suggest the Ability of Participatory Video to Reduce Gender-based Violence in Conflict-affected Settings. Health Ed Res 29(4): 690-701. http://dx.doi.org/10.1093/her/cyu018

4. Ward J, J Brewer. 2004. Gender-based Violence in Conflict-affected Settings: Overview of a MultiCountry Research Project. Forced Migr Rev 19: 2628.

5. UNHCR. 2019. Sexual and Gender Based Violence. www.unhcr.org/sexual-and-gender-based-violence.html

6. Alsaba K, A Kapilashrami. 2016. Understanding Women's Experience of Violence and the Political Economy of Gender in Conflict: The Case of Syria. $R H$ Matters 24(47): 5-17. https://doi.org/10.1016/j.rhm.2016.05.002

7. UNFPA. 2016. Sexual and Gender-based Violence Assessment in North East Nigeria. https://reliefweb.int/sites/reliefweb.int/files/resources /sgbv_assessment.pdfa COUNCIL 